\title{
O DILETANTISMO INGLÊS: O VIOLINO NA CULTURA BRITÂNICA NO SÉCULO XVII
}

\begin{abstract}
Marcus Held ${ }^{1}$
RESUMO:

A música para violino é tema recorrente em diversas pesquisas da musicologia histórica. No entanto, uma abordagem mais detalhada sobre os primeiros passos de seu repertório carece de atençáo. Desde seu aparecimento na renascença tardia, a música para violino esteve ligada à música de dança. Seja nas tavernas, nas casas, ou nas ruas, a posição que esse instrumento conquistou na sociedade levou-o a um papel de destaque nas cortes europeias. $\mathrm{Na}$ Inglaterra, foco deste artigo, o violino serviu, primeiramente, como instrumento integrante das English Masques e dos consorts reais. Isto deu ao violino e sua família maior autonomia de repertório, de modo que este passou a atuar em gêneros essencialmente instrumentais, como a fantasia-suíte, a sonata e o trio-sonata. Neste estudo, observaremos como o instrumento em questáo influenciou o panorama da dança na Inglaterra do século XVII, utilizando-se de obras de compositores representativos daquele período: John Playford (1623-1687) e Peter Prelleur (1705-1741). Em seguida, estudaremos, com mais detalhes, os gêneros citados previamente, a fim de esclarecer a relação do violino para com o estilo italiano em ascensão, bem como sua execução pelos músicos amadores, fundamentais para o desenvolvimento da popularidade e reputação desse instrumento além de sua perpetuação na cultura britânica
\end{abstract}

\section{PALAVRAS-CHAVE:}

violino; música Instrumental; Inglaterra; século XVII.

\section{ABSTRACT:}

Violin music is a common theme on many historical musicology surveys. However, a more detailed approach about the first steps of its repetoire lacks attention. Since its appearance in late Renais-
1. Departamento de Música (CMU), Escola de Comunicaçóes e Artes (ECA),Universidade de São Paulo (USP). Este trabalho foi financiado pela FAPESP - Fundação de apoio à Pesquisa do Estado de Sáo Paulo (Processo no 2015/066689). As opiniōes, hipóteses e conclusôes ou recomendaçóes expressas neste material são de responsabilidade do autor e não necessariamente refletem a opiniáo da FAPESP. Email: mvheld@ usp.br. 
sance, violin music had been related to dance music. Be it in taverns, homes or streets, the position wich this instrument acquired took him to a leading role in european courts. In England, the focus of this work, the violin served, firstly, as an instrument of the English Masques and of the royal consorts. This gave the violin and its family greater autonomy in its repertoire, acting on essencially instrumental genres as the fantasy-suite, the sonata and the trio-sonata. In this research, therefore, we will observe how the instrument in question influenced the dance panorama in 17th century England, using works of representative composers of that period: John Playford (1623-1687) and Peter Prelleur (1705-1741). Secondly, we will study, with more details, the previouly cited instrumental genres for the sake of clarification of the relation between the violin and the ascending italian style, as well as the performance by the amateur musician, wich were fundamental to the development of the popularity and the reputation of that instrument., besides its perpetuation in British culture.

\section{KEYWORDS:}

violin; instrumental music; England; seventeenth century.

O violino, nos estudos de musicologia histórica, é sempre lembrado como um instrumento genuinamente italiano. De fato, ao considerarmos construtores emblemáticos como Amati, Stradivari e Guarneri, bem como os compositores de sonatas e concertos, como Corelli, Vivaldi e Geminiani, não restam dúvidas sobre a relação que o violino possui com seu país de origem. No entanto, em países como a Inglaterra, a música instrumental apoiou-se, ao longo do século XVII e início do século XVIII, na escrita para a música de câmara, cujo protagonista foi, também, o violino.

Embora seja o foco de poucos pesquisadores, a Inglaterra foi o berço de uma profusáo cultural singular, cuja diversidade artística pode ser evidenciada nos inúmeros manuais, métodos e tratados destinados ao estudo autodidata desse instrumento que foram publicados por lá. Essas obras

São extremamente interessantes de um ponto de vista social e histórico. Elas oferecem uma boa indicação do gosto musical de um dado período, mostram claramente o desenvolvimento da técnica instrumental ao longo dos anos e as mudanças nas for- 
mas dos instrumentos, bem como oferecem muita informação valiosa sobre a performance ${ }^{2}$. (SIMPSON, 1966, p. 25)

Deste modo, o primeiro passo deste artigo, tendo em vista exuberância editorial que a Inglaterra ofereceu ao púbico ao longo dos setecentos, serão observados os manuais de John Playford (1623-1687), The Dancing Master (1651) e The Appolo's Banquet (1669), e de Peter Prelleur (1705-174), The Modern-Musick Master (1731). Neles, é evidente o papel fundamental que a dança exerceu na cultura britânica daquele período. Em seguida, será estudado o desenvolvimento da linguagem instrumental que se sucedeu a partir desse fenômeno da música popular, que chegou às cortes por meio da English Masque e das formaçóes de consort. Ainda no ramo da música de câmara, o estilo italiano, encabeçado por um dos maiores músicos daquele tempo, Arcangelo Corelli (1653-1713), passou a atuar, pouco a pouco, no panorama musical inglês. Os primeiros passos nesta direçáo foram dados, principalmente, por Henry Purcell (1659-1685), que introduziu de maneira definitiva na Inglaterra o modelo italiano de composição.

\section{O VIOLINO E SUA RELAÇÃO COM A DANÇA NO SÉCULO XVII}

A história do violino na Inglaterra está, desde o seu princípio, relacionada com a França: em ambos os países, esse instrumento exerceu papel fundamental na música de dança (BOYDEN, 1990, p. 138). Com efeito, foram diversas as obras e coletâneas que relacionavam o violino à dança publicadas na Inglaterra ao longo dos séculos XVII e XVIII; entre elas, destacam-se The Dancing Master (1651) e The Appolo's Banquet (1669), de John Playford (1623-1687), bem como The Modern-Musick Master (1731), de Peter Prelleur (17051741).

Playford é uma das personalidades mais importantes e presentes do século XVII na Inglaterra. Violinista, compositor e, principalmente, editor, publicou, a partir dos anos 1650 até sua morte, dezenas de obras, compêndios e tratados dedicados à música popular, cujo instrumento protagonista era, na maioria dos casos, o violino. Embora seja pouco lembrado nos dias atuais, a obra desse músico é o ponto de partida para
2. "[these tutors] are extremely interesting from a social and historical point of view. They provide a good indication of the musical taste of any given period, show clearly the development in instrumental technique through the years and the changing fashions in instruments, and provide much valuable information about performance practise". Nossa tradução. 
o estudo da música de dança em seu país de origem (CALDWELL, 1991, p. 554). Uma de suas primeiras obras, The English Dancing Master, é um importante documento para a cultura britânica, uma vez que descreve, detalhadamente, todas as danças comuns daquela época, além de escrever em partitura uma a uma, contabilizando mais de uma centena de exemplos. Em The Appolo's Banquet "contendo as melodias usuais de danças francesas executadas na corte e nas escolas de dança" (HOLMAN, 1993, p. 314), Playford dedica as primeiras páginas a ensinar o iniciante a tocar violino, descrevendo como segurar o instrumento, o arco, como direcionar este último em relaçáo às cordas, bem como a ensinar o leitor a ler partitura. O segundo estágio é onde reside, porém, a maior importância dessa obra: os exemplos musicais, exclusivamente de danças populares, para que o aprendiz possa praticar. A obra representa um dos maiores acervos da música de dança na Inglaterra, visto que contém 121 exemplos. Já a obra citada de Peter Prelleur, apesar de publicada muitos anos depois que as de Playford, contém a mesma estrutura: as primeiras páginas são dedicadas ao ensino do instrumento, seguindo os mesmos passos que o anterior, mas com mais detalhes na explicação e exemplificação. Ao fim do tratado, dezenas de danças populares são oferecidas para o aprendiz praticar. Tal obra deve ser mencionada, uma vez que, como Boyden sabiamente demonstrou (1960, p. 44), as informações contidas na seção $\mathrm{V}$ de The Modern Musick Master, isto é, The Art of Playing on the Violin é, na verdade, a cópia de um material de autor anônimo de 1695, intitulado Nolens Volens, demonstrando que sua atuação nesse gênero teve duraçáo prolongada.

Além do sempre mencionado papel importante que a dança exerceu na vida burguesa, desde a Antiguidade, vale ressaltar que o violino, justamente por seu uso popular, ganhou paulatinamente apreço na corte inglesa seiscentista. Assim, no reino de James I, de 1603 a 1625, o músico Thomas Lupo foi contratado para servir como "compositor para o violino", e suas músicas deveriam oferecer para a banda real maior variedade, para o deleite do monarca (BOYDEN, 1990, p. 138). Anos mais tarde, durante o domínio de Charles I, de 1625 a 1649, esta orquestra já contabilizava catorze integrantes, uma grande quantidade para aquele tempo. Nesse ambiente, o papel do violino esteve, muitas vezes, ligado ao teatro, exe- 
cutando música incidental (os primeiros registros datam de 1561). Além disso, outro evento social importante no âmbito aristocrático, cujo retorno foi testemunhado no reinado de James I, foi a English Masque (HOLMAN, 1993, p. 179), notável por unir dança e atuação. Sobre o gênero, Boyden (1990, p. 138) comenta que, "tais Masques desfrutaram de grande popularidade, e, já que a dança e a representaçáo teatral ocuparam posiçáo central em suas apresentaçóes, o violino fora um instrumento favorecido". Vale lembrar que outras atrações, como vestimentas elaboradas e acessórios luxuosos, chamavam a atenção da aristocracia britânica. Embora essas formaçóes instrumentais fossem, em sua maioria, integradas por músicos profissionais, o âmbito diletante era muito influente na Inglaterra, e o violino, antes tocado por camponeses e músicos de rua, passou a ser também o instrumento da nobreza, o que justifica a publicaçáo de dezenas de manuais.

\section{GÊNEROS INSTRUMENTAIS}

Embora o papel do violino na música de dança seja claramente observado na grande quantidade de material publicado no próprio século XVII, gêneros instrumentais como a fantasia-suíte, a sonata e o trio-sonata devem ser observados individualmente, pois canalizaram o curso da música instrumental para o estilo italiano, cujo ponto culminante iria acontecer no século XVIII, com a figura de Francesco Geminiani (1687-1762). Antes de mencioná-los, debrucemo-nos, primeiramente, sobre a música para consort, uma formação instrumental que, desde o período elisabetano, teve papel fundamental para a construção do gosto musical daquele país.

Prática recorrente em diversos países da cultura ocidental, a música para conjunto de instrumentos, ou consort esteve em voga na Inglaterra de 1580 até o início do século XVII, tendo exercido um papel crucial nessa cultura durante o reinado de Elizabeth I. De fato, Buelow (2004, p. 293) explica:

A música inglesa, em toda a sua diversidade, começou a desenvolver um caráter nacional antes do período elisabetano, mas a segunda metade do século XVI solidificou os aspectos estilísticos elusivos daquelas qualidades "inglesas", com uma grande explosão de música. Foi um período especialmente de música secular. O madrigal importado da Itália foi recriado dentro de 
3. "English music in all its diversity began to develop a national character even before the Elizabethan period, but the second half of the sixteenth century solidified the elusive stylistic aspects of those "English" qualities in a great outburst of music. It was a period especially of secular music. The madrigal imported from Italy was recreated into an English concept, and vocal forms such as consort songs and other polyphonic songs flourished. Instrumental music for lute, cittern, bandora, for consort of strings, virginals, all were composed in great numbers and those forms continued without interruption into the seventeenth century." Nossa tradução. um conceito inglês, e formas vocais como cançóes em consort e outras cançóes polifônicas floresceram. Música instrumental para alaúde, cistre, pandora, para consort de cordas, virginais, todas foram compostas em grande número, e essas formas continuaram a existir, sem interrupção,no século XVII. ${ }^{3}$

Existiam dois tipos de consort: Whole Consort: gênero mais importante da música instrumental do período, constituía-se de instrumentos de diversos tamanhos de uma mesma família. Eram muito comuns consorts de cornetos e sacabuxas (instrumentos fortes), ou de flautas doces, violinos e violas da gamba (instrumentos fracos). Esse último, em peculiar, era muito apreciado pela nobreza, sendo digno de obras dos compositores mais respeitados de toda a Europa. Já o Broken Consort era constituído, basicamente, de instrumentos de famílias diferentes. Embora bastasse que quaisquer instrumentos não pertencentes à mesma família se unissem em qualquer quantidade para constituírem um broken consort, uma formaçáo em particular popularizou-se no território inglês, sendo esta formada por um traverso (ou uma flauta doce), uma viola da gamba soprano (ou um violino), um cistre, um alaúde, uma pandora e uma viola da gamba baixo (ATLAS, 1998, p. 687. Compositores como Phillip Rosseter e Thomas Morley contribuíram muito para o repertório dessa formação instrumental tipicamente inglesa, também conhecida como six severall instruments (ZWILLING, 2003, p. 49). De acordo com a extensa pesquisa de Zwilling sobre a música na época de Shakespeare, o Broken consort "teve uma atuação proeminente, principalmente como grupo instrumental acompanhante das danças, festividades, além das mascaradas táo caras ao gosto do público" (ZWILLING, 2003, p. 50).

No século XVII, surgiu a fantasia-suíte, um gênero de música para consort que, com formação instrumental tipicamente inglesa, representa o amálgama da tradiçáo polifônica, estabelecida na fantasia para consort, e da dança, cujo destaque na cultura britânica foi discorrido anteriormente. Em geral, era escrita para um ou dois violinos, viola da gamba baixo e órgão, e seus movimentos consistiam de uma "fantazya" inicial, seguida de dois ou três movimentos de dança. Entre seus diversos compositores, destacam-se John Coperario (1570-1626) que, tendo estudado na Itália, foi pioneiro ao introduzir o violino no gosto musical inglês, inspirando os músicos de geraçôes 
seguintes, e William Lawes (1602-1645). Em suas composiçôes, é possível testemunhar o início da linguagem violinística em ascensão, uma vez que exploram as capacidades técnicas do instrumento cuja linguagem era nova no país.

Embora a instrumentação da fantasia-suite assemelhe-se ao da sonata italiana, deve-se ter em mente que sáo dois gêneros instrumentais distintos, que ocorreram paralelamente nos dois países. A primeira desenvolve uma linguagem característica da Inglaterra. Neste sentido, se as considerássemos análogas às sonatas italianas, estaríamos negando o desenvolvimento do gosto musical daquele país. No entanto, não há como negar uma forte influência italiana, uma vez que a sonata, assim como o estilo italiano como um todo, chegou à Inglaterra de maneira definitiva nos anos 1650, com a obra de William Young (d. 1662) e de Henry Purcell (1659-1685). Embora o primeiro tenha sido um dos primeiros autores de sonatas daquele país, toda sua obra fora publicada na Áustria, país onde viveu a maior parte de sua vida. Purcell, no entanto, representa um rompimento genuíno com o passado. Em suas sonatas em três partes de 1683, o compositor elabora uma harmonia inglesa peculiar, mas a linguagem instrumental, a elaboração técnica e, principalmente, o gosto, são italianos, visto que suas referências foram peças de Cazzati, Vitali, Lelio Colista, Matteis, Bononcini e Corelli (BOYDEN, 1990, pp. 237-238). Tanto esse opus de trio-sonatas quanto o de 1697 abarcam o conhecimento do compositor enquanto autor de fantasias polifônicas ao estilo da antiga tradição. No entanto mesmo quando utiliza um idioma inglês em sua música para violino, o modelo e a inspiração são italianas. Esse procedimento será copiado nas próximas geraçóes de compositores daquele país, e culminará com a imigração de violinistas italianos na primeira metade do século XVIII, como Francesco Maria Veracini e Francesco Geminiani. O gosto musical dominante será aquele de Arcangelo Corelli, que, ainda em vida, viu seu estilo propagado por todo o continente europeu.

\section{CONSIDERAÇÓES FINAIS}

O presente artigo teve como objeto de estudo a música instrumental para violino durante o século XVII. Nesse contexto, vale notar que a contribuição que sua participação 
em expressóes populares como a dança colaborou para sua inserção nas cortes aristocráticas. De fato, como afirma Holman (1993), o apreço que o violino obteve nas cortes inglesas fica evidente em sua participação nos diversos conjuntos instrumentais que atuaram por lá, que executando peças de dança, em especial aquelas protagonizadas na English Masque, gênero tipicamente inglês. As obras de John Playford e de Peter Prelleur observadas neste trabalho representam uma rica fonte de informação para o estudo da música britânica do século XVII, pautada pela influência da corte de Luis XIV.

Vimos, ainda, que a chegada do gosto italiano, modelado em Corelli, proporcionou alteraçóes substanciais na música inglesa, com o advento do trio-sonata, fato especialmente notável na obra de Young e de Purcell. A escrita italiana somou-se, em solo inglês, ao estilo britânico contrapontístico, oriundo da fantasia-suite e da música para consort. Neste artigo, mostramos que, na música de Purcell, a harmonia é inglesa, mas a roupagem, a escrita e a técnica instrumental, são italianas. Ficou evidenciado também, que a migração de diversos violinistas-compositores italianos para a Ilha na primeira metade do século XVIII, foi essencial para consolidar essas alteraçóes estilísticas.

Vale lembrar que o enorme sucesso que o violino obteve na Inglaterra deve-se, antes de tudo, ao ambiente propício para seu florescimento: o âmbito diletante. Hábito próprio daquele país, as inúmeras publicaçóes de manuais para aprendizado autodidata em música proporcionaram aos instrumentos, ainda que lentamente, seu desenvolvimento técnico. Assim, cumpre notar que, diferentemente de outros centros musicais, como a França e a Itália, as formas musicais inglesas referenciadas neste artigo foram, sempre, executadas por músicos amadores, sendo eles burgueses ou aristocratas. Assim, a Inglaterra testemunhou, ao longo do século XVII, a ascensão de um instrumento que, antes coadjuvante nas classes sociais mais baixas, passou a protagonista nas cortes britânicas, além da expansão do estilo italiano, que passou a predominar em quase toda a Europa, sobre o gosto francês. 


\section{REFERÊNCIAS BIBLIOGRÁFICAS}

ATLAS, Allan N. Renaissance Music: Music in Western Europe. New York/London: W. W. Norton Company, 1998.

BOYDEN, David. The History of Violin Playing From its Origins to 1761 and its Relationship to the Violin and Violin Music. New York: Oxford University Press, 1990.

. A Postscript to the first Violin Tutor. Acta

Musicologica, 32, p. 40-47. Basel: International Musicological Society, 1960.

BUELOW, George J. A History of Baroque Music: Music in the seventeenth and the first half of the eighteenth centuries. Bloomington: Indiana University Press, 2004.

CALDWELL, John. The Oxford History of English Music: volume I: From the Beginnings to c. 1715. Oxford: Oxford University Press. 1991.

HOLMAN, Peter. Four and Twenty Fiddlers: The Violin at the English Court (1540-1690). Oxford: Clarendon Press, 1993.

SIMPSON, Adrienne. A Short-Title of Printed English Instrumental Tutors up to 1800, Held in British Libraries. In: R. M. A Research Chronicle. New York, Taylor \& Francis Ltd, 1966, p. 24-50 (v.6).

ZWILLING, Carin, As Cançóes de Cena de William Shakespeare - resgate das cançôes originais, transcrição e indicaçóes para tradução. Tese (Doutorado em Letras). Faculdade de Filosofia, Letras e Ciências Humanas (FFLCH), Universidade de São Paulo (USP), São Paulo, 2003. 